\title{
Advanced Gastroesophageal Junction Adenocarcinoma
}

National Cancer Institute

\section{Source}

National Cancer Institute. Advanced Gastroesophageal /unction Adenocarcinoma. NCI

Thesaurus. Code C159548.

Gastroesophageal junction adenocarcinoma that has spread extensively to other anatomic sites or is no longer responding to treatment. 